\title{
Clinical Practice: Clinical Images Fungating Mass as First Presentation of Advanced Breast Cancer
}

\author{
Caroline E. McCoach, MD, PhD and Paul Aronowitz, MD \\ Department of Internal Medicine, University of California, Davis, Sacramento, CA, USA.
}

KEY WORDS: breast cancer; metastatic cancer; locally advanced breast cancer; healthcare resources.

$\mathrm{J}$ Gen Intern Med 29(4):685

DOI: $10.1007 / \mathrm{s} 11606-013-2600-4$

(C) Society of General Internal Medicine 2013

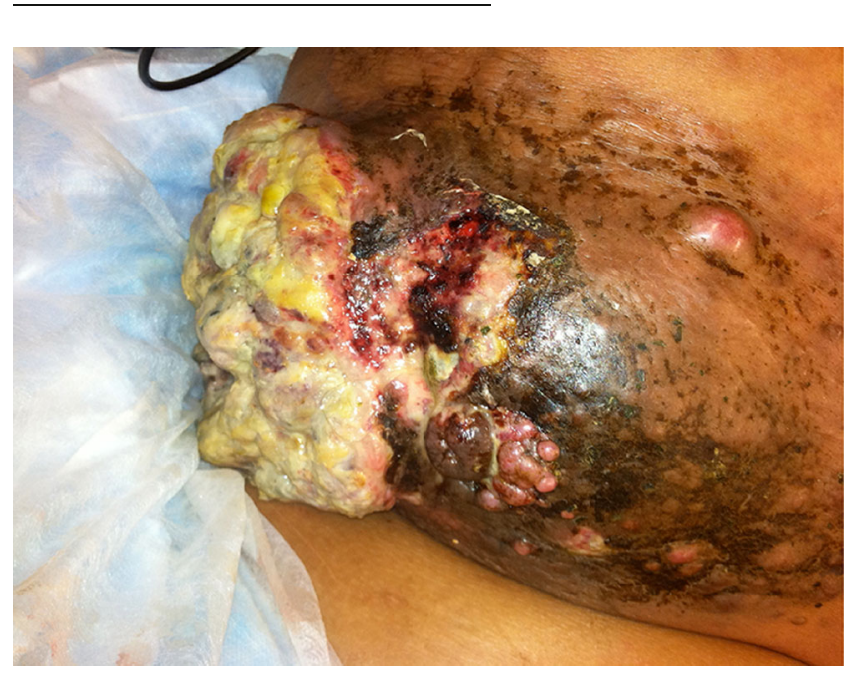

Figure 1. Necrotic right breast mass.

\begin{abstract}
A 52-year-old woman visiting from the nation of Tonga presented to the Emergency Department with shortness of breath and an enlarging right breast mass that she first noticed one year prior to evaluation. Physical examination revealed a pulse of 120 beats $/ \mathrm{min}$, a respiratory rate of 40 breaths $/ \mathrm{min}$ and a necrotic right breast mass, measuring $15 \mathrm{~cm} \times 7.5 \mathrm{~cm}$ (Fig. 1). Diminished breath sounds and dullness to percussion were noted at the right posterior chest. Computed tomography of the chest showed one dominant (Fig. 2, X) and multiple smaller lesions in the right breast; a right-sided pleural effusion (Fig. 2, asterisk); nodular pleural thickening (Fig. 2, arrowhead); lung parenchymal nodules (Fig. 2, arrow); and diffuse lymphadenopathy. Biopsy demonstrated infiltrating poorly differentiated ductal adenocarcinoma. While fungating breast masses are considered locally advanced disease (stage III), she was diagnosed with stage IV breast cancer due to the presence of distant metastases. ${ }^{1-3}$ Globally, breast cancer incidence is increasing. ${ }^{4,5}$ In developing countries $>60 \%$ of women present with later stage cancers (III/
\end{abstract}

Received April 29, 2013

Revised June 19, 2013

Accepted August 15, 2013

Published online September 25, 2013

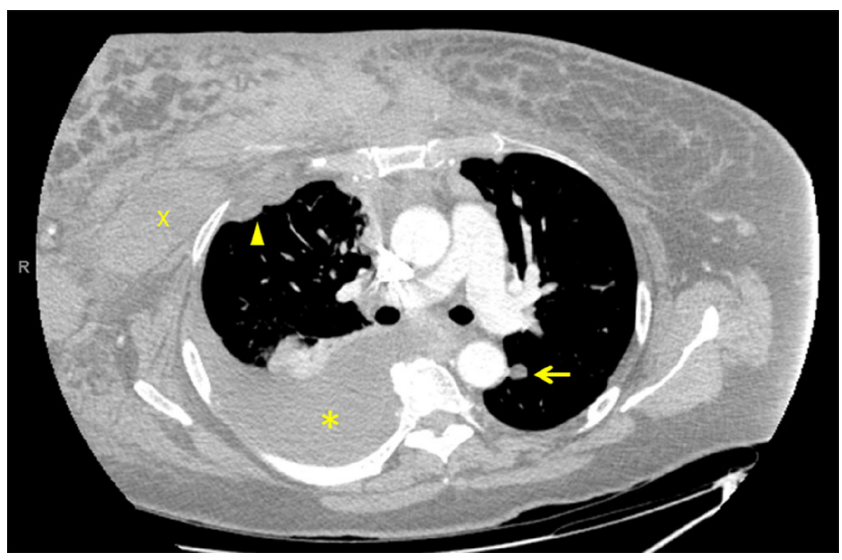

Figure 2. Computed tomography of the chest showing one dominant $(\mathrm{X})$ and multiple smaller lesions in the right breast; a right-sided pleural effusion (asterisk); nodular pleural thickening (arrowhead); lung parenchymal nodules (arrow); and diffuse lymphadenopathy.

IV). ${ }^{4}$ In one case series, $39 \%$ of 212 patients presented with fungating breast masses. ${ }^{6}$ This patient was subsequently discharged with palliative care follow-up.

Conflict of Interest: The authors declare that they do not have a conflict of interest.

\section{Funding: None}

Corresponding Author: Paul Aronowitz, MD; Department of Internal Medicine, University of California, Davis, $4150 \mathrm{~V}$ Street, Suite 3100, Sacramento, CA 95817, USA (e-mail: Paul.aronowitz@ucdmc.ucdavis.edu).

\section{REFERENCES}

1. Singletary SE, Allred C, Ashley P, et al. Revision of the American Joint Committee on Cancer staging system for breast cancer. J Clin Oncol. 2002;20(17):3628-36.

2. Newman LA. Epidemiology of locally advanced breast cancer. Semin Radiat Oncol. 2009;19(4): 195-203.

3. Giordano SH. Update on locally advanced breast cancer. Oncologist. 2003;8(6):521-30.

4. Hortobagyi GN, de la Garza SJ, Pritchard K, et al. The global breast cancer burden: variations in epidemiology and survival. Clin Breast Cancer. 2005;6(5):391-401.

5. Youlden DR, Cramb SM, Dunn NA, et al. The descriptive epidemiology of female breast cancer: an international comparison of screening, incidence, survival and mortality. Cancer Epidemiol. 2012;36(3):237-48.

6. Adesunkanmi AR, Lawal OO, Adelusola KA, Durosimi MA. The severity, outcome and challenges of breast cancer in Nigeria. Breast. 2006;15(3):399-409. 